\title{
EFFECTS OF CHEMICALLY TREATED AND CARBONIZED SPEAR GRASS FIBRE ON THE CURING AND MECHANICAL PROPERTIES OF NATURAL RUBBER VULCANIZATES
}

\author{
A. C. Ezika ${ }^{1, *}$ and V. U. Okpechi ${ }^{2}$ \\ 1, 2, Dept. of Polymer and Textile EngR'G, Nnamdi AZikiWe Univ. AWKa, ANAmbra State, NigeRIA \\ Email addresses: 1 ac.ezika@unizik.edu.ng, 2 uv.okpechi@unizik.edu.ng
}

\begin{abstract}
Effects of chemically treated and carbonized spear grass fibre on the curing and mechanical properties of natural rubber vulcanizates were carried out. Natural rubber (NR) was filled with carbonized (at carbonization temperatures of $400^{\circ} \mathrm{C}, 600^{\circ} \mathrm{C}$ and $800^{\circ} \mathrm{C}$ respectively) and chemically treated (treatment with $\mathrm{HCl}$ and $\mathrm{NaOH}$ of $5 \%$ concentration) spear grass fillers respectively, at a filler loading of 30phr. The rubber compounding was carried out in a bambury mixer. The effect of carbonization temperature and chemical treatment of the filler on the mechanical properties (tensile strength, \% elongation, hardness strength, abrasion resistance and compression set) and rheological properties (cure time, scorch time, maximum and minimum torque) were carried out on the samples. The results of the mechanical properties of carbonized spear grass fibre (C-SGF) filled vulcanizates show that the optimum carbonization temperature for an improved tensile strength, \% elongation, hardness, abrasion and compression set was obtained at $400^{\circ} \mathrm{C}$. $\mathrm{NaOH}$ treated fibre filled vulcanizates showed better mechanical properties; with the highest abrasion resistance of $67.65 \%$, while untreated and acidified fibre filled vulcanizates showed poor mechanical properties. Acidified (HCI) uncarbonized spear grass fibre (U-SGF) filled vulcanizate had the highest compression set of 48\% against C-SGF filled vulcanzates and carbon black filled vulcanizate, with carbon black filled vulcanizate having $47 \%$ as its compression set value. This reveals that at a carbonization temperature of $400^{\circ} \mathrm{C}, \mathrm{C}$-SGF appears to be a potential substitute filler for carbon black (CB).
\end{abstract}

Keywords: Spear Grass Fibre, Natural Rubber, Chemical Treatments, Cure Characteristics, Mechanical Properties, Carbonization

\section{INTRODUCTION}

The quest for means and alternative for improving the properties and processing of natural rubber (NR) dates back to over a century ago. One way of achieving this extension of service life of natural rubber (NR) is the incorporation of additives into the polymer matrix [1], another approach involves the choice and temperature of carbonization of additives (fillers) as a means of enhancing natural rubber (NR) usage [2].

Fibre treatment which was microscopically observed helps to align fibre strands, thereby controlling particle distribution. Use of alkali or acid can improve filler dispersion [3].

Furthermore, if the particle size can be controlled by adjusting the temperature of carbonization, thereby increasing the surface area of filler particles, a better result may be found. This study has been undertaken with the objective of observing the effect of carbonization temperature of natural grass fibre (Imperata cylindrical) as an alternative filler in natural rubber (NR) compounding, adopting cost effective alternatives.

Additives are material when incorporated into a polymer base (natural rubber base), help to ensure

* Corresponding author, tel + 234 - $803-245-9497$ 
easy processing, increase the properties of natural rubber, reduce the cost of natural rubber and enhance service properties [4]. The different types of additives used in the processing of natural rubber (NR) into products include vulcanizing agents, accelerator, activator, anti-degradants, fillers, softeners, thickeners, gel sensitizer, colourant etc. [5].

Fillers is one of the major additives used in natural rubber (NR) compound and has marked effect and influence on rubber materials. Filler functions are to modify the physical and, to some extent, the chemical properties of vulcanizates [6-7].

The mechanism of reinforcement of elastomers by fillers has been reviewed by several researchers [8], it was considered that the effect of fillers is to increase the number of chains which share the load of a broken polymer chain. It is known that in the case of filled vulcanizates that the efficiency of reinforcement depends on a complex interaction of several filler related parameters such as particle size, particle shape, particle dispersion, surface area, surface reactivity, structure of the filler and the bonding quality between the filler and the rubber matrix [9].

Fillers in elastomers and plastics also reduce the cost of the end product and modify the electrical and optical properties of the polymer matrix [10].

In rubber industry, fillers that are commonly in use are carbon black, china clay and calcium carbonate. Carbon black is derived from petrochemical sources but the unstable price of crude oil has led to the search for fillers that are derived from other sources [5-7]. Agricultural by-products; maize cobs, cocoa pod husk, sugar cane chaff, rice-husk, plantain peel etc. are low cost materials and readily available in large quantity, with potentials for use as fillers. In previous reports, the use of cocoa pod husk, rubber seed shells [11-12], groundnut husk, plantain peels etc. were also examined, the results obtained from these studies indicated a potential for the utilization of agricultural residues as fillers in natural rubber compounds. In this present study, the effect of spear grass (Imperata Cylindrical) fibre on the cure characteristics and mechanical properties of natural rubber vulcanizate are examined.

\section{MATERIALS AND METHODS}

\subsection{Materials}

The natural rubber crumbs conforming to Nigerian Standard Rubber (NSR) grade 10 was obtained from
Rubber Research Institute of Nigeria (RRIN), Iyanamo, Benin City.

The rubber compounding chemicals such as zinc oxide, stearic acid, processing oil, N330 carbon black, sulphur, mercaptobenizothiazolesulphanamide (MBTS), Ncyclohexyl benzothiazole-2-Sulphonamide (CBS), 2, 2, 4-trimethyl-1, 2-d, hydroquinoline (TMQ) were of commercial grades. All reagents were used as obtained from Rubber Research Institute of Nigeria (RRIN) without further purification.

Spear grass (Imperata cylindrical) fibre were obtained from agricultural farm of Umuoka, Ogbede, Enugu State, Nigeria.

\subsection{Filler Preparation}

A Spear grass (Imperata cylindrical) fibre used for the research was obtained from Ogbede Enugu state agricultural farm land. Raw fibres as received contained dust and husk; therefore it was subjected to a thorough cleaning process. Firstly, the raw fibres were dusted in open air before being cleansed by using water to remove the dust and impurities present. This was followed by oven drying for 24 hours at $40^{\circ} \mathrm{C}$. Next, the fibres were gently combed unidirectional and placed on a clean paper sheet.

\subsubsection{Chemical treatment of spear grass fibres}

The cleaned fibres were then separately soaked in one litre sodium hydroxide $(\mathrm{NaOH})$ and one litre hydrochloric acid $(\mathrm{HCl})$ of $5 \%$ concentration each for 12 hours at room temperature. After that, the fibres were taken out of their respective treatments and rinsed using distilled water.

The fibres were then dried in an oven at 4 for 24 hours. Finally, the untreated and treated fibres were cut to the desired lengths $(100 \mathrm{~mm})$ for test specimen preparations.

It is to be noted here that the idea of using $\mathrm{NaOH}$ and $\mathrm{HCl}$ treated samples is to explore the possibility of promoting high adhesion strength of the spear grass fibre by means of "chemical coupling" the treated fibres to the polymer resin. Although it is generally known that acidic treatment could destroy the natural fibre by means of acidic deterioration, though some research works stated the opposite [13].

\subsubsection{Carbonization of spear grass fibres}

The large quantity of washed and dried spear grass fibre was milled to a fine powder using electric 
milling machine, the ground fibre was thereafter, sieved with a mesh of size $75 \mu \mathrm{m}$ and retained by a $90 \mu \mathrm{m}$ mesh size. The fine particles that passed through the mesh were collected as uncarbonized spear grass (U-SGF) fibre powder. The remaining portion was weighed and carbonized at a temperatures of $400^{\circ} \mathrm{C}, 600^{\circ} \mathrm{C}$ and $800^{\circ} \mathrm{C}$ for each set of the remaining fibres for a hold-up time of 3 hours using an electric oven set at 3 different temperatures as described by [11-14]. The carbonized fibres were then milled and sieved through a $75 \mu \mathrm{m}$ mesh sieve. The fine black powder that passed through the mesh was then collected as carbonized spear grass fibre black powder. Both carbonized (C-SGF) and uncarbonized spear grass fibre (U-SGF) powder were characterized in terms of $\mathrm{pH}$, particle size and moisture content.

\subsection{Compounding}

Mixing was carried out on a laboratory two-roll mill in accordance with the method described in the American Society for Testing and Materials (ASTMD3184 -80). The compounding was done at the temperature of $50^{\circ} \mathrm{C}$, speed of $20 \mathrm{rpm}$ and a mixing time of 20 minutes.

Table 1: Recipe for compounding the natural rubber

\begin{tabular}{lc}
\multicolumn{2}{c}{ mixes } \\
\hline Ingredient & Phr (parts per hundred) \\
\hline Natural rubber & 100 \\
Stearic acid & 2.0 \\
Zinc oxide & 5.0 \\
TM Q & 2.0 \\
MBTs & 1.0 \\
CBs & 1.6 \\
Sulphur & 1.5 \\
Filler & 30 \\
\hline
\end{tabular}

\subsection{Cure Characteristics}

The cure characteristics of the compound mixes were measured at $150^{\circ} \mathrm{C}$ on an Oscillating Disc Rheometer (ALPHA ODR 2000) in accordance with the ISO 3417 method.

The cure time $\left(t_{90}\right)$, scorch time $\left(t_{1}\right)$, minimum torque (tmin), and maximum torque (tmax) were determined from the rheographs. The cure rates were determined using:

$$
\text { Cure rate }=\frac{100\left(S^{-1}\right)}{T_{90}-t_{1}}
$$

Where: $T_{90}=$ optimum cure time, $t_{1}=$ minimum scorch time.

\subsection{Physico-Mechanical Properties 2.5.1 Tensile strength}

Tensile properties of the vulcanizates were measured with a Monsanto tensile tester (model $1 / \mathrm{m}$ ) with a cross head speed of $500 \mathrm{~mm} / \mathrm{min}$ using dumb bell test pieces measuring $30 \mathrm{~mm} \times 4 \mathrm{~mm} \times 2 \mathrm{~mm}$ according to ASTMD-412-87 (method A). The tensile strength at break was calculated at the elongation at break. The recorded value for each tensile parameter is the average of three measurements.

\subsubsection{Hardness strength}

Hardness was obtained with a Durometer following the ASTM D676-52T procedure. The procedure involved placing the equipment on the dumb bell flat test pieces and recording the hardness in international rubber hardness Degree (IRHD) when a little force was applied. This procedure was repeated for each sample and the average value taken.

\subsubsection{Abrasion resistance}

Wallace Akron tester was used in accordance with BS method. The test piece was weighed and taken to the braider for braiding, the test piece was braided for 1000 revolutions, after which it was re-weighed to get the \% loss of Abrasion compared to the standard test piece. The equation (2) gives the abrasion resistance index

Abrasion resistance index $=\frac{S}{T} \times 100 \%$

Where: $\mathrm{S}=$ Volume loss per 1000 revolution of abrasive wheel on standard test piece $\left[230 \mathrm{~mm}^{3}\right]$. T $=$ Volume loss per 1000 revolutions of abrasive wheel on test piece.

\subsubsection{Compression set}

Compression set test was conducted in accordance with the ASTMD 395 - 03. Compression set test include a constant load (method A) and constant deflection (method B) as a compressive means. Compression set was determined by method $A$ for various samples using a disc sample $1.5 \mathrm{~mm}$ (thickness) $\times 25 \mathrm{~mm}$ (diameter) by placing the samples in the compression parallel plate and the samples were compressed to the spacer thickness retained after $24 \mathrm{hrs}$ with force of $145 \mathrm{~N}$ at a temperature of $70^{\circ} \mathrm{C}$. The compression set (Cs) in the samples was calculated by the difference in the original thickness of the specimen and the thickness after distortion load has been removed and allowed 
to recover for 30 minutes. The compression set was calculated using equation below.

$$
C_{S}=\frac{T_{0}-T_{1}}{T_{0}-T_{2}} \times 100
$$

\section{RESULTS AND DISCUSSION}

The physical properties of spear grass fibre show that $\mathrm{pH}$ of the slurry ranges from 7.9 to 8.01 for carbonized as the temperature increases, this may be as a result of change in temperature which increases the carbon content of the sample. The uncarbonized spear grass fibres have higher values for moisture content as a result of its origin, which is the major problem of its use as a reinforcement.

\subsection{Cure Characteristics of Spear Grass Filled Natural Rubber}

For C-SGF filled Vulcanizates, C-SGFV at has the fastest cure rate at 0.63 per second. This may be due to its high moisture content $[2,8,15]$, when compared with C-SGFV at which has 0.56 per second, followed by C-SGFV at with the lowest cure rate of 0.47 per second. The increase in carbonization temperature tends to decrease the cure rate as a result of decrease in moisture content. The high cure rate of C-SGFV at will result to increase in its elasticity owing to its high cross linking density as compared with CB-N330 vulcanizate with 0.57 $\sec ^{-1}$.

Finally, a faster cure rate is obtained with fillers having a low surface area, high moisture content and smaller particle size [16]. The difference in cure characteristics may be attributed to the fact that each filler possesses different filler properties such as surface area, surface reactivity and structure [917].
From the figure 2, acidified fibre filled vulcanizate with $4: 16$ (mins:sec) as the cure time which is considerably higher than that of CB-N330 vulcanizate is expected to have poor mechanical properties when compared with CB-N330. The increased cure time as noticed in acidified fibre filled vulcanizatemay be as a result of deteriorating action of acid on fibre structure, thereby pro-longing the time for optimum curing of the vulcanizate. The untreated fibre filled vulcanizate with 3:17 (mins: sec) as cure time is likely to have better mechanical properties as compared to acidulated fibre filled vulcanizate. The high values of acidulated and alkalized fibre filled vulcanizates cure time, allow a processing safety, thereby creating new application areas. This is as a result of fibre treatment which aligns the fibre dimensionally, for a proper curing.

The minimum torque (ML) and maximum torque (MH) which is directly proportional to the viscosity of the vulcanizing compound at any given temperature, characterize the stiffness of the vulcanizates at the beginning and end of the vulcanization process. The lowest and highest torque values are observed in the case of CB-N330 vulcanizate which has $7.38 \mathrm{~kg}-\mathrm{cm}$ as $\mathrm{ML}$ and $39.24 \mathrm{~kg}-\mathrm{cm}$ as $\mathrm{MH}$, followed by alkalized fibre filled vulcanizate with $29.11 \mathrm{~kg}-\mathrm{cm}$ as $\mathrm{ML}$ and $38.24 \mathrm{~kg}-\mathrm{cm}$ as MH. Finally, the untreated SGF vulcanizate which has $8.04 \mathrm{~kg}-\mathrm{cm}$ and 29.38 as ML and $\mathrm{MH}$ respectively, is expected to be less viscous/stiff when compared with CB-N330, acidulated and alkalized fibre filled vulcanizate. Based on the statistical theory of rubber elasticity, stiffness which is directly proportional to torque is a function of modulus.

This implies that increase in modulus increases torque, showing an increase in tensile strength which is proportional to modulus.

Table 2: Physical properties of carbon black, carbonized and uncarbonized spear grass fibre

\begin{tabular}{|c|c|c|c|c|c|c|c|}
\hline \multirow{3}{*}{ Properties } & \multirow{3}{*}{$\begin{array}{l}\text { Carbon black } \\
\text { (CB-N330) }\end{array}$} & \multirow{2}{*}{\multicolumn{3}{|c|}{$\begin{array}{l}\text { Carbonized spear grass fibre (C- } \\
\text { SGF) }\end{array}$}} & \multicolumn{3}{|c|}{$\begin{array}{c}\text { Uncarbonized spear grass fibre powder (U- } \\
\text { SGF) }\end{array}$} \\
\hline & & & & & \multirow{2}{*}{$\begin{array}{l}\text { Un- } \\
\text { Treated }\end{array}$} & \multicolumn{2}{|c|}{ Treated } \\
\hline & & $400^{\circ} \mathrm{C}$ & $600^{\circ} \mathrm{C}$ & $800^{\circ} \mathrm{C}$ & & $\begin{array}{c}\text { Alkalized } \\
(\mathrm{NaOH})\end{array}$ & Acidified(HCL) \\
\hline $\begin{array}{l}\mathrm{pH} \text { of slurry at room } \\
\text { temperature }\end{array}$ & 8.90 & 7.90 & 8.00 & 8.01 & 6.10 & 6.80 & 5.40 \\
\hline Particle size $(\mu \mathrm{m})$ & 75 & 75 & 75 & 75 & 75 & 75 & 75 \\
\hline Moisture Content (\%) & 0.02 & 0.05 & 0.04 & 0.02 & 7.01 & 7.01 & 6.90 \\
\hline Loss on Ignition (\%) & $89: 80$ & 85.40 & 73.00 & 69.80 & 35.60 & 35.60 & 35.60 \\
\hline
\end{tabular}


Table 3: Cure characteristics of carbon black (CB-N330), carbonized spear grass fibre (C-SGF) and uncarbonized spear grass fibre (U-SGF) filled natural rubber at a filler load of 30 phr.

\begin{tabular}{llllllll}
\hline \multirow{2}{*}{ Cure characteristics } & CB-N330 filled & \multicolumn{2}{c}{ C-SGF filled vulcanizate } & \multicolumn{2}{c}{ U-SGF filled vulcanizate } \\
\cline { 3 - 8 } & vulcanizate & $400^{\circ} \mathrm{C}$ & $600^{\circ} \mathrm{C}$ & $800^{\circ} \mathrm{C}$ & Untreated & Alkalized & Acidified \\
\hline Cure rate $(\mathrm{sec})$ & 0.57 & 0.63 & 0.56 & 0.47 & 0.57 & 0.64 & 0.50 \\
Cure time $(\mathrm{m}: \mathrm{s})$ & $3: 35$ & $3: 06$ & $3: 14$ & $3: 20$ & $3: 17$ & $3: 52$ & $4: 16$ \\
$\begin{array}{l}\text { Scorch time }(\mathrm{m}: \mathrm{s}) \\
\begin{array}{l}\text { Minimum torque rate } \\
\text { (kg-cm) }\end{array}\end{array}$ & $0: 39$ & $0: 27$ & $0: 17$ & $0: 12$ & $0: 26$ & $1: 15$ & $0: 57$ \\
$\begin{array}{l}\text { Maximum torque rate } \\
\text { (kg-cm) }\end{array}$ & 7.83 & 14.39 & 10.23 & 8.54 & 8.04 & 29.11 & 22.39 \\
Temperature $\left({ }^{\circ} \mathrm{C}\right)$ & 150.24 & 38.97 & 35.35 & 29.44 & $29: 38$ & $38: 24$ & $36: 47$ \\
\hline
\end{tabular}

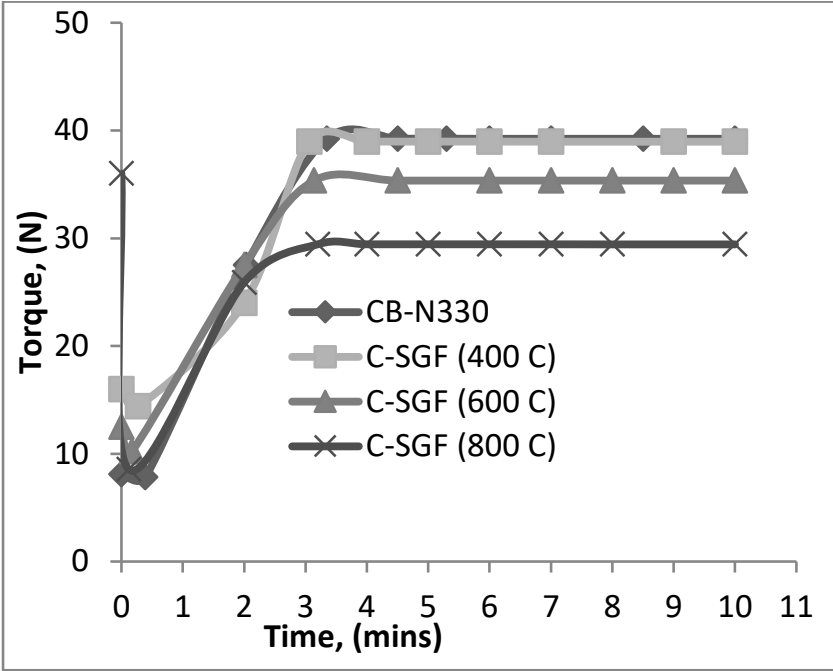

Fig. 1: Plot of Torque versus Time for C-SGF and CB-N330 filled Vulcanizates.

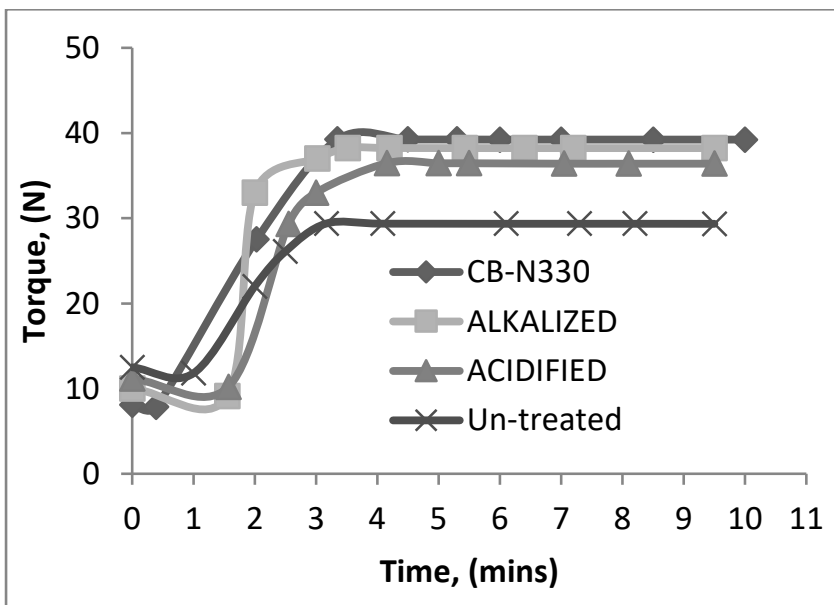

Fig.2: Plot of Torque versus Time for U-SGF and CB-N330 filled Vulcanizate

\subsection{Physico-Mechanical Properties of Spear Grass Fibre Filled Vulcanizates}

\subsubsection{Tensile strength}

Figure 3 shows the tensile strengths of the vulcanizates at a different force load. At an initial loading of $50 \mathrm{~N}$, both $\mathrm{CB}-\mathrm{N} 330$ vulcanizate which serves as a control, C-SGFV at $400^{\circ} \mathrm{C}$ and C-SGFV at $600^{\circ} \mathrm{C}$ have the same tensile strength of $6.25 \mathrm{MPa}$, while C-SGFV at $800^{\circ} \mathrm{C}$ has the lowest tensile strength as 4.16 MPa. As the load increases, CB N330 vulcanizate attained its maximum tensile strength as $15.30 \mathrm{MPa}$, at force load of $122.40 \mathrm{~N}$ beyond which it started decreasing.

C-SGFV at $400^{\circ} \mathrm{C}$ also attained its maximum tensile strength of $15.05 \mathrm{MPa}$ at a load of $120.40 \mathrm{~N}$, beyond which it started decreasing. It was observed that CSGFV at $800^{\circ} \mathrm{C}$ has the lowest tensile strength of $5.10 \mathrm{MPa}$ at force loading of $40.8 \mathrm{~N}$. The decrease in the tensile strength of the C-SGF vulcanizates may be attributed to increasing in carbonization temperature, which may have destroyed the filler particle structure and a hydrophilic surface chemistry of the filler.

Tensile strength is affected by particle structure and particle surface chemistry, that is, better particle structure and hydrophilic surface enhance the tensile strength of a vulcanizate [18].

Fig. 4 shows the decrease in tensile strength of the vulcanizates from treated to untreated fibre filled vulcanizates.

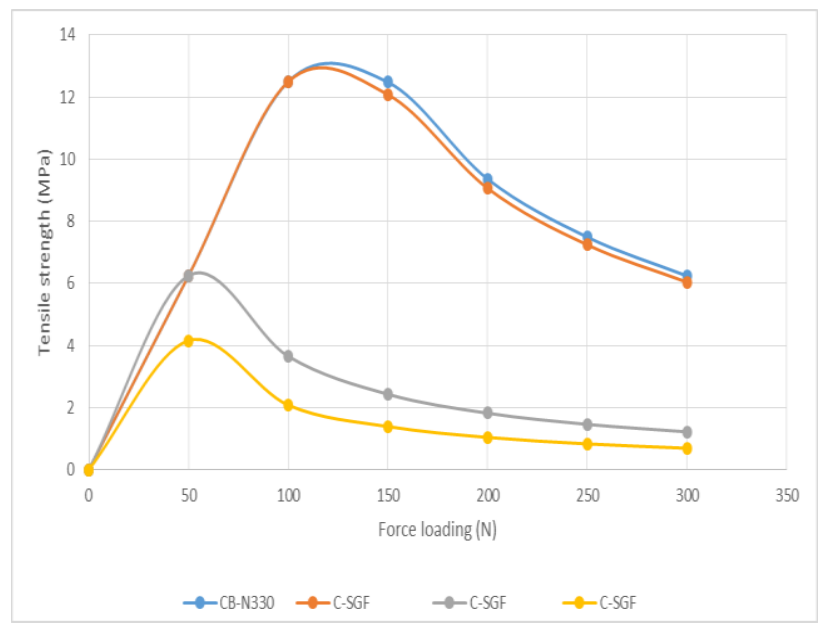

Fig.3: Plot of tensile strength versus force loading of C-SGF and CB-N330 filled vulcanizates 


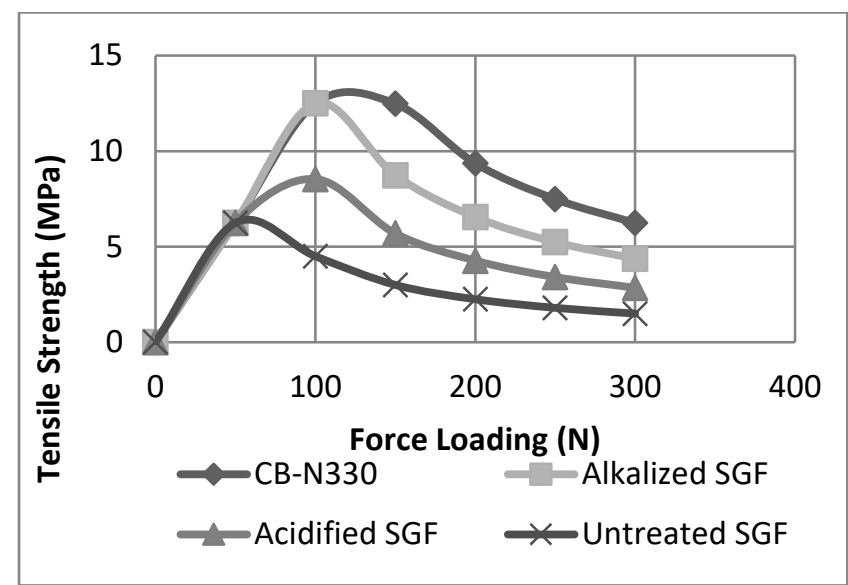

Fig 4: Plot of tensile strength versus force loading of U-SGF filled vulcanizates

Comparing $\mathrm{CB}-\mathrm{N} 330$ vulcanizates with tensile strength of $15.30 \mathrm{MPa}$ at $122.4 \mathrm{~N}$ force loading, alkalized fibre filled vulcanizate attained its maximum tensile strength at $12.80 \mathrm{MPa}$ at a load of $102.40 \mathrm{~N}$, followed by acidified fibre filled vulcanizate with $10.33 \mathrm{MPa}$ as tensile strength at a load of $82.64 \mathrm{~N}$.

The un-treated fibre filled vulcanizate attained its maximum tensile strength at 7.5MPa on a load of $60 \mathrm{~N}$; the lowering of the tensile strength may be as a result of poor filler dispersion and the nature of the filler surface chemistry which could be improved by fibre treatment [19].

Alkali treatment of the fibre has improved the fibre surface chemistry as well as its dispersion in the polymer matrix, as reported by [3-14].

\subsubsection{Percentage elongation at break (Eb)}

It was observed in table 5, that elongation at break decreases with increase in carbonization temperature of C - SGF filled vulcanizates. The decrease in elongation at break has been explained interms, of filler structure and adherence to the polymer phase, leading to the stiffening of the polymer chain and enhanced resistance to stretch when strain is applied [8-16].

Table 6, shows the \% elongation at break (Eb) for $U$ - SGF filled vulcanizates at optimum tensile strength and filler load of $30 \mathrm{phr}$. The alkalized SGF filled vulcanizate showed a higher \% elongation at break (Eb) of $1111 \%$, followed by acidified - SGF filled vulcanizate with $711.67 \%$, while untreated - SGF filled vulcanizate has the least $\%$ Eb of $542.2 \%$.

\subsubsection{Hardness Strength}

Generally, hardness increases with increasing filler content. It is expected because as more filler particles get into the rubber, the elasticity of the rubber chain is reduced, resulting in more rigid vulcanizates [5]. From Table 4.8, the hardness of $\mathrm{CB}-\mathrm{N} 330$ vulcanizate is superior to those of C-SGF filled vulcanizate with $60-63$ (IRHD) while untreated SGF filled vulcanizate has the least hardness strength of 49 (IRHD).

\subsubsection{Compression set}

The amount by which the test piece reverts to its original thickness was measured and recorded as compression set. Compression set reduced with increasing temperature of carbonization; this may be attributed to filler particle structure destruction as the temperature increases. Whereas compression set is maximum at 48 when the filler is treated with $\mathrm{HCl}$ solution, and this may be due to the stiffening of the filler particles by the acid treatment.

Table 5: Percentage elongations at break of CB - N330 and C - SGF filled vulcanizates at optimum tensile strength.

\begin{tabular}{lcccc}
\hline & $\begin{array}{c}\text { Filler loading } \\
(\mathrm{phr})\end{array}$ & $\begin{array}{c}\text { Tensile strength } \\
(\mathrm{Mpa})\end{array}$ & $\begin{array}{c}\text { Force } \\
(\mathrm{N})\end{array}$ & $\begin{array}{c}\text { Maximum Elongation at break } \\
(\%)\end{array}$ \\
\hline $\mathrm{CB}-\mathrm{N} 330$ & 30 & 15.30 & 122.40 & 1299.00 \\
$\mathrm{C}-\mathrm{SGF}\left(400^{\circ} \mathrm{C}\right)$ & 30 & 15.05 & 120.4 & 1201.00 \\
$\mathrm{C}-\mathrm{SGF}\left(600^{\circ} \mathrm{C}\right)$ & 30 & 6.75 & 54.00 & 405.50 \\
$\mathrm{C}-\mathrm{SGF}\left(800^{\circ} \mathrm{C}\right)$ & 30 & 5.10 & 40.00 & 382.30 \\
\hline
\end{tabular}

Table 6: Percentage elongations at break of Uncarbonized (U-SGF) Filled vulcanizates at the optimum tensile

\begin{tabular}{lcccc} 
& \multicolumn{5}{c}{ strength } \\
& $\begin{array}{c}\text { Filler loading } \\
(\mathrm{phr})\end{array}$ & $\begin{array}{c}\text { Tensile strength } \\
(\mathrm{Mpa})\end{array}$ & $\begin{array}{c}\text { Force } \\
(\mathrm{N})\end{array}$ & $\begin{array}{c}\text { Maximum Elongation at break } \\
(\%)\end{array}$ \\
\hline Alkalized SGF & 30 & 12.80 & 102.40 & 1111.00 \\
Acidified SGF & 30 & 10.33 & 82.64 & 711.67 \\
Untreated SGF & 30 & 7.50 & 60.00 & 542.20 \\
\hline
\end{tabular}


Table 7: Hardness Strength of Vulcanizates at Optimum Tensile Strength.

\begin{tabular}{llccc}
\hline & & $\begin{array}{c}\text { Filler loading } \\
\text { (phr) }\end{array}$ & $\begin{array}{c}\text { Tensile strength } \\
\text { (MPa) }\end{array}$ & $\begin{array}{c}\text { Hardness Strength } \\
\text { (IRHD) }\end{array}$ \\
\cline { 2 - 5 } Carbonized SGF & 30 & 15.30 & $60-63$ \\
\hline \multirow{3}{*}{ Uncarbonized } & At $400^{\circ} \mathrm{C}$ & 30 & 15.05 & $50-63$ \\
SGF & At $600^{\circ} \mathrm{C}$ & 30 & 6.75 & $55-60$ \\
& At $800^{\circ} \mathrm{C}$ & 30 & 5.10 & $50-52$ \\
\hline & Alkalized SGF & 30 & 12.80 & $49-50$ \\
& Acidified SGF & 30 & 10.33 & 50 \\
& Untreated & 30 & 7.50 & 49 \\
\hline
\end{tabular}

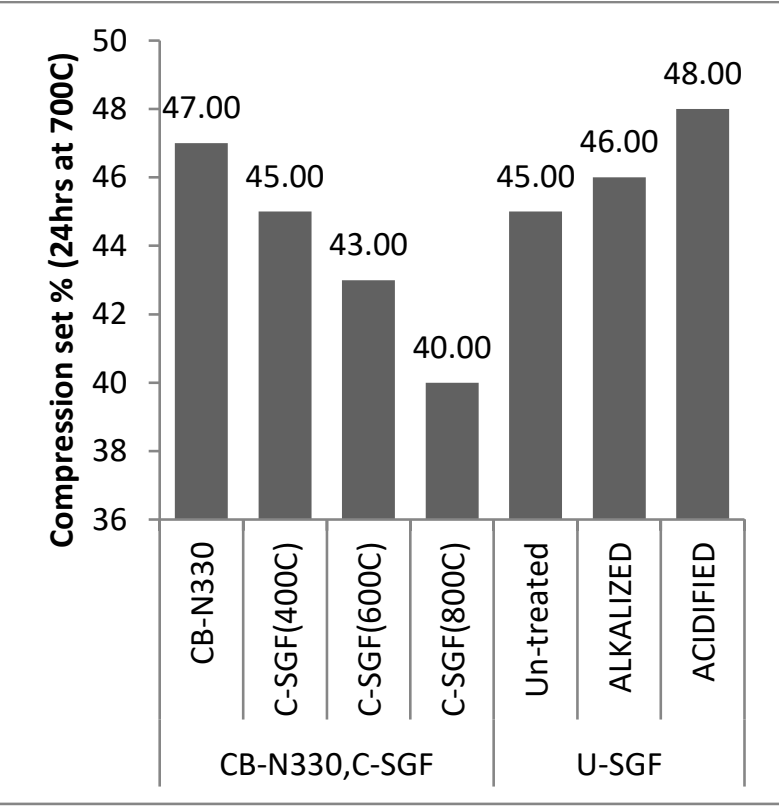

Figure 5: Plot of Compression set versus $C B$ N330, C-SGF and U - SGF filled vulcanizates.

\section{CONCLUSION}

The vulcanizates properties of spear-grass fibre filled Natural Rubber (NR) can be improved by carbonization of the spear grass fibre at $400^{\circ} \mathrm{C}$, but increasing the temperature of carbonization of SGF above $600^{\circ} \mathrm{C}$ limits the vulcanizates mechanical properties.

Beyond $400^{\circ} \mathrm{C}$, the particle size tends to decrease for a better polymer-filler matrix, however, the particle structure and particle surface chemistry are destroyed due to the increase in temperature. Also, increasing the temperature decreases the moisture content of the filler, leading to a lower cure rate which results in the formation vulcanizates of fewer cross-links with poor mechanical properties.

This findings, therefore, reveals that C-SGF at $400^{\circ} \mathrm{C}$ can serve as a potential substitute for $\mathrm{CB}$, especially for the production of low cost/high volume rubber products where strength is not critical.

All properties tested were significantly affected by the chemical treatments given to the SGF, alkalized
SGF filled vulcanizate showed a better vulcanizate properties as against untreated and acidulated SGF filled vulcanizates.

In the area of application where abrasion resistance is paramount and \% elongation not critical, alkalized SGF filled vulcanizate with highest abrasion resistance of $67.65 \%$ is better used, this is as a result of the hindrance in the chain mobility of the particle due to the alkaline treatment of SGF filled vulcanizate

\section{REFERENCES}

[1] Byars, J. A. "Flow properties of natural rubber composites filled with deflated soy flour "Applied polymer science, 111(4), 2004, 2049 - 2055.

[2] Michael, J. A., and William, S. L. M. "Thermal Degradation of Rice husk in Nitrogen atmosphere" Bio-resources Technology, 65, 2008, 13-20.

[3] Nasir, M. and Choo, Ch. "Chemical Modification of Natural; rubber Latex with peracetic acid, Enr. Polym. J., 2002, 25-355.

[4] Ski, KB. Engineering Material, properties and selection. Resion Publishing Company, 2004.

[5] Okieimen, F.E. and Imanah J.E. "Characterization of agricultural waste products as fillers in natural rubber formulation". Nig. J. Polym. Technol, 3(1), 2009, pp 201.

[6] Drivers, W. E. Plastic Chemistry and Technology. Van Nostrand Company. London, 2007, p 243.

[7] Bernnan, J. J., and Jermyn, T. E. "Properties of black reinforced blends of natural rubber and butadiene rubber" Journal of Applied Science, 9, 2007, 27-45.

[8] Parkinson, D. Reinforcement of Rubbers. Lakeman and Co. London, 2007, pp 12. 
[9] Davis, J. R. Tensile testing. Springer handbook of materials measurement methods. Berlin: Springer, 2004.

[10] Patterman, M. Q. "Chemortheology of model filled rubber compound during curing" Rubber World Journal, 5, 2001, 194-38.

[11] Ishak, Z. and Baker, A. A. "An Investigation of the potential of rice husk ash as fillers epoxidized natural rubber" Enr. Polym. J. 31, 2003, pp 259.

[12] Mansary, K. G., and Ghaly, A. E."Thermal Degradation of Rice husk in Nitrogen atmosphere" Bio-resources Technology, 65, 1999, 13-20.

[13] Hephbum, G. and Blow C. M. Rubber Technology and Manufacture $3^{\text {rd }}$ Edition. Butter worth Publishing. 188. 1998.

[14] Rivin, D. Polymer-filler interaction in rubber reinforcement. Rubber Chem. Tech. 36:729, 1999.
[15] Akporhonor, E., and Okieimen, F. "Effect of Coconut Fibre filler on the cure characteristics physic - mechanical and swelling properties of natural vulcanizates" International Journal of Physical Sciences 2(2), 2007, 039-046.

[16] Baranwal, P. C. "Research on reinforcing of natural rubber with modified carbon black" International Carbon Black Association, New York: 2 (10).2001.

[17] Gent, N., and Lui, G.L. "Swelling and electrical properties of rubber vulcanizates loaded with paraffin wax" Journal of Polymer. Science Polym. Phys, 29, 2002, $1313-1319$.

[18] Honday, M. Composite material. Elsevier, New York. 1021, 1996.

[19] Marik, H. F. Encyclopedia of Polymer Sciences and Technology. Interscience, New York. 12:42, 2000. 